\title{
The impact of women's empowerment on their children's early development in 26 African countries
}

\author{
Fernanda Ewerling ${ }^{1,2}$, \\ John W Lynch ${ }^{3,4}$, Murthy \\ Mittinty ${ }^{3}$, Anita Raj ${ }^{5}$, Cesar \\ G Victora $^{1,2}$, Carolina VN \\ Coll $^{1,2}$, Aluisio JD Barros ${ }^{1,2}$ \\ ${ }^{1}$ International Center for Equity \\ in Health, Federal University of \\ Pelotas, Pelotas, Brazil \\ ${ }^{2}$ Postgraduate Program in \\ Epidemiology, Federal University of \\ Pelotas, Pelotas, Brazil \\ ${ }^{3}$ School of Public Health, University \\ of Adelaide, Adelaide, SA, Australia \\ ${ }^{4}$ Population Health Sciences, Bristol \\ Medical School, University of \\ Bristol, Bristol, UK \\ ${ }^{5}$ Center on Gender Equity and \\ Health, University of California San \\ Diego, San Diego, California, USA
}

\section{Correspondence to:}

\section{Aluísio J D Barros}

Postgraduate Programme of

Epidemiology

Marechal Deodoro 1160

3rd floor, 96020-220

Pelotas, RS

Brazil

abarros@equidade.org
Background Every year more than 200 million children under-five years fail to achieve their full developmental potential in low- and middle-income countries (LMICs). Although women's empowerment has been associated with improved child health and development outcomes, this is a topic little studied in LMICs. We investigated the associations between women's empowerment and early childhood development among a sample population of 84537 children aged 36-59 months from national health surveys of 26 African countries.

Methods We used data from Demographic and Health Surveys (DHS) and Multiple Indicator Cluster Surveys (MICS) ranging from 2010 to 2018. Four developmental domains were assessed among children using the Early Childhood Development Index: literacy-numeracy, physical, learning and socioemotional. Women's empowerment in attitude to violence, social independence and decision-making was evaluated using the SWPER global, a validated survey-based index. We reported effect sizes for each country and a combined estimate of the association. The study covers all countries with surveys in the region and uses a novel approach for measuring women's empowerment, the SWPER.

Results Across all countries, 15.1\% of the children were on track in the literacy-numeracy domain, $92.3 \%$ in physical, $81.3 \%$ in learning and $67.8 \%$ in socio-emotional. The odds of a child being on track in literacy-numeracy increased by $34 \%$ (odds ratio $(O R)=1.34 ; 95 \%$ confidence interval $(C I)=1.31-1.37$ ), $88 \%(\mathrm{OR}=1.88 ; 95 \% \mathrm{CI}=1.85-1.91)$ and $34 \%(\mathrm{OR}=1.34 ; 95 \% \mathrm{CI}=1.29$ 1.39), with a one standard deviation increase in the scores of attitudes to violence, social independence and decision-making domains of empowerment, respectively. No effect of empowerment was observed for the other domains of child development.

Conclusions Our results show a consistent positive effect of empowerment on the literacy-numeracy domain of child development cross-nationally in Africa and this was particularly evident for the social independence domain of the SWPER. Programs and interventions may also consider addressing the reduction of gender inequalities to improve child development.

Every year more than 200 million children under-five years of age from low- and middle-income countries (LMICs) fail to achieve their full potential in cognitive development, most in south Asia and sub-Saharan Africa [1]. In 2015, the international community embraced this cause, including universal access to early childhood development (ECD), care and preprimary education as a target on the Sustainable Development Goals (SDGs). This signals an important change relative to the earlier Millennium Development Goals, which only targeted child survival. International 
organizations, governments and policy makers are now committed to guarantee that all children are able to not only survive, but also thrive [2]. The first five years of the child's life are critical for their cognitive, social, and physical development [3]. This period is an important window for investments, since interventions focused on ECD are among the most cost-effective approaches to increase educational achievements and productivity in adulthood.[2,4] Failing to promote child development may also sustain the intergenerational transmission of poverty $[1,5]$.

The family environment is a key determinant of child survival and optimal development [5], which comprises, among other factors, a stimulating environment, social interactions with dedicated caregivers and adequate nutrient intake $[4,6]$. Poverty, discrimination, conflict and other forms of individual, family and community stress create barriers for families to provide nurturing care for children and may compromise their ability to parent effectively [7]. This may be exacerbated in contexts where gender inequalities and women's marginalization are common [8,9]. In LMICs, many women are still deprived of claiming their rights and of being able to make decisions about the direction of their lives and those of their children $[10,11]$. With potential to promote economic growth, reduction of poverty and being an important accomplishment of human rights, the empowerment of women is also targeted by the SDGs [12]. More empowered women are more likely to use modern contraceptives and to have access to antenatal care and skilled birth attendance [13-17]. They also generally desire a smaller number of children, which should allow them to provide better care to each child $[18,19]$. Data on ECD are still limited in LMICs. UNICEF recently started collecting data on the Early Childhood Development Index (ECDI), which allows the assessment of four developmental domains: literacy-numeracy, physical, socioemotional and learning. To our knowledge, no study has ever evaluated the association between the mothers' empowerment level and ECD in LMICs. This study adds to the literature by analyzing this association in African countries, which may present high gender inequalities and low levels of child development $[6,20]$.

\section{METHODS}

We used data from Multiple Indicator Cluster Surveys (MICS) and Demographic and Health Surveys (DHS) as both have similar questionnaires and sampling strategies. Items to assess ECD have been added to the MICS questionnaires since 2009, and in some DHS since 2010 [21]. We selected the latest survey for each African country for which the ECD module had been applied, either in MICS or DHS. A total of 26 countries were included (see Table 1 ).

\section{Early child development}

Early child development was measured by the ECDI developed by UNICEF intended for cross-cultural comparisons. This is a multidimensional index composed of ten questions directed to the child's mother or primary caregiver designed to assess the development of children aged 36 to 59 months [4]. The ECDI covers four developmental domains: literacy-numeracy, physical, learning and social-emotional. The response categories for all questions are "yes", "no", and "don't know". For each domain, the child is considered on track according to the number of items with affirmative answers. For example, the literacy-numeracy domain is composed of three items (child can identify/name at least ten letters of the alphabet; child can read at least four simple, popular words; and child knows the name and recognizes the symbol of all numbers from 1 to 10). The child is considered on track in this domain if at least two of these three items are achieved. Overall, the child is considered developmentally on track if at least three of the four domains were considered on track. The complete description of the ECDI questions and its operationalization to determine whether the child is developmentally on track in each domain is presented in Box 1. We analyzed each ECDI domain separately and the composite ECDI score according to this operationalization.

\section{Women's empowerment}

Mother's empowerment was measured by the Survey-based Women's emPowERment (SWPER) global index [22]. This is an individual level measure which assesses three domains of empowerment: attitude to violence, social independence and decision making. It is based on 14 questions related to the women's responses on whether beating the wife is justified in some situations, to who makes decisions in the household (regarding the respondent's health care, large expenses and visits to family and relatives), access to information, educational attainment, age at marriage and first child, and differences in age and education relative to the husband (Table S1 in the Online Supplementary Document). The SWPER global 
Table 1. Sample sizes and prevalence (\%) of children aged 36-59 months who are developmentally on track in literacy-numeracy, physical, learning and social-emotional domains, and in the Early Child Development Index

\begin{tabular}{|c|c|c|c|c|c|c|c|c|c|}
\hline \multirow[b]{2}{*}{ Region } & \multirow[b]{2}{*}{ Country } & \multicolumn{8}{|c|}{ \% CHILREN 36-59 MONTHS WHO ARE ON traCK BY DEVELOPMENTAL DOMAIN* } \\
\hline & & Year & Source & $\begin{array}{l}\text { Literacy- } \\
\text { numeracy }\end{array}$ & Physical & Learning & $\begin{array}{l}\text { Social- } \\
\text { emotional }\end{array}$ & $\mathrm{ECDI} \dagger$ & $\begin{array}{c}\text { Sample } \\
\text { size } \ddagger\end{array}$ \\
\hline \multirow{6}{*}{$\begin{array}{l}\text { Eastern \& Southern } \\
\text { Africa }\end{array}$} & Burundi & 2016 & DHS & 9.1 & 92.6 & 63.7 & 59.2 & 41.1 & 4254 \\
\hline & Eswatini & 2014 & MICS & 20.6 & 93.7 & 93.6 & 64.9 & 66.8 & 512 \\
\hline & Malawi & 2013 & MICS & 17.6 & 89.3 & 80.5 & 72.0 & 60.8 & 5893 \\
\hline & Rwanda & 2014 & DHS & 7.3 & 95.2 & 86.2 & 81.9 & 71.3 & 2240 \\
\hline & Uganda & 2016 & DHS & 29.1 & 90.9 & 86.8 & 67.3 & 64.7 & 4129 \\
\hline & Zimbabwe & 2014 & MICS & 9.9 & 92.4 & 87.1 & 65.1 & 59.9 & 2813 \\
\hline \multirow{2}{*}{$\begin{array}{l}\text { Middle East \& North } \\
\text { Africa }\end{array}$} & Algeria & 2012 & MICS & 28.2 & 96.1 & 89.3 & 70.3 & 69.9 & 5033 \\
\hline & Tunisia & 2018 & MICS & 39.9 & 95.7 & 91.6 & 81.4 & 82.8 & 1384 \\
\hline \multirow{18}{*}{ West \& Central Africa } & Benin & 2017 & DHS & 8.7 & 87.4 & 71.9 & 68.9 & 53.8 & 4170 \\
\hline & Central African Republic & 2010 & MICS & 7.1 & 95.5 & 74.1 & 58.1 & 46.6 & 2905 \\
\hline & Cameroon & 2011 & DHS & 17.2 & 92.8 & 82.5 & 52.4 & 49.8 & 1641 \\
\hline & Chad & 2014 & DHS & 5.3 & 83.5 & 54.0 & 59.5 & 32.1 & 3826 \\
\hline & Congo Brazzaville & 2011 & DHS & 12.8 & 87.5 & 80.3 & 55.5 & 49.1 & 1968 \\
\hline & Congo DR & 2013 & DHS & 10.4 & 92.2 & 79.9 & 78.3 & 64.5 & 2458 \\
\hline & Cote d'Ivoire & 2016 & MICS & 6.9 & 95.0 & 87.0 & 70.0 & 63.5 & 2677 \\
\hline & Gambia & 2018 & MICS & 13.3 & 94.0 & 93.5 & 66.3 & 65.2 & 3500 \\
\hline & Ghana & 2011 & MICS & 29.3 & 97.4 & 89.4 & 74.3 & 75.1 & 2329 \\
\hline & Guinea & 2016 & MICS & 6.6 & 92.2 & 78.8 & 62.0 & 48.8 & 2530 \\
\hline & Guinea-Bissau & 2014 & MICS & 7.2 & 89.8 & 86.8 & 72.7 & 61.1 & 2081 \\
\hline & Mali & 2015 & MICS & 7.9 & 94.4 & 84.6 & 73.1 & 61.9 & 5601 \\
\hline & Mauritania & 2015 & MICS & 26.1 & 90.7 & 79.1 & 66.4 & 59.6 & 3367 \\
\hline & Nigeria & 2016 & MICS & 28.2 & 89.8 & 77.5 & 71.2 & 60.7 & 9699 \\
\hline & São Tome \& Principe & 2014 & MICS & 16.9 & 94.0 & 78.5 & 61.0 & 53.8 & 568 \\
\hline & Senegal & 2017 & DHS & 4.4 & 95.3 & 86.3 & 75.0 & 66.5 & 3618 \\
\hline & Sierra Leone & 2017 & MICS & 14.3 & 89.8 & 79.7 & 59.6 & 51.2 & 3318 \\
\hline & Togo & 2013 & DHS & 8.4 & 92.6 & 70.4 & 75.4 & 53.9 & 2053 \\
\hline Overall & & & & 15.1 & 92.3 & 81.3 & 67.8 & 59.0 & 84537 \\
\hline
\end{tabular}

ECDI - Early Child Development Index, DHS - Demographic and Health Surveys, MICS - Multiple Indicator Cluster Surveys

*Please see Box 1 for the items included in each developmental domain.

$†$ Children are considered developmentally on track on the Early Child Development Index (ECDI) if they are on track in at least three of the four developmental domains.

¥Children aged 36-59 months living with the mother; restricted to partnered mothers.

Box 1. Operationalization of the Early Child Development Index (ECDI) in children aged 36-59 months.

(1) Literacy-numeracy: Children are considered developmentally on track if at least two of the following are true: Can identify/name at least ten letters of the alphabet; can read at least four simple, popular words; knows the name and recognizes the symbol of all numbers from 1 to 10 .

(2) Physical: Children are considered developmentally on track if one or both of the following is true: can pick up a small object with two fingers, like a stick or a rock from the ground; is not sometimes too sick to play.

(3) Learning: The child is identified as being developmentally on track if one or both of the following is true: follows simple directions on how to do something correctly; when given something to do, is able to do it independently.

(4) Social-emotional: The child is identified as being developmentally on track if at least two of the following are true: gets along well with other children; does not kick, bite, or hit other children; does not get distracted easily.

Overall, the child is developmentally on track if at least three of the four component domains were considered to be on track [4].

provides continuous standardized scores, so that a zero score means that the woman is at an average level of empowerment compared to the set of low- and middle-income countries used to develop the revised version of the index. A positive score indicates higher empowerment than average and a negative score, the opposite. Full details on the construction of the index and its validity are presented elsewhere [22,23]. 


\section{Missing data}

Some women did not have complete information on all the items needed to calculate the SWPER global scores and some surveys included in this analysis did not collect information on some variables required for calculating the SWPER global. For instance, MICS does not provide the husband's education nor any information on the woman's participation in household decisions. To overcome the husband's education issue, we used the schooling of the head of the household as a proxy for the husband's education, and other missing variables were imputed. We used multiple imputation for these missing variables by design (questions not included in the survey questionnaire) and for those cases where the answers for individual women were missing. We assumed that the data were missing at random. We pooled the data from the 26 countries used in this analysis with data from the latest DHS conducted in each African country since 2010 with available information on all SWPER variables (these surveys collected information on the SWPER items but not on child development). By doing so the imputation model relied on a much larger sample. Thus, multiple imputation was performed in this data set that contained information on 493764 partnered women from 41 African countries. In the pooled data set, 38\% of the women ( $\mathrm{n}=187521)$ had missing information for at least one SWPER item (varying from 100\% in MICS, that do not collect any information on decision-making, to $8.9 \%$ in DHS surveys). The literature advocates that five imputed data sets are generally sufficient, but up to 20 data sets are preferable to deal with the sampling variability from the imputation process. Given the considerably high proportion of missing cases in our data, we decided to impute 20 data sets. The SWPER items and the outcome of interest (ECDI) with missing information were imputed based on country, wealth index, and area (urban/rural) of residence, woman's age and the outcome of interest (ECDI). Women in the attitude to violence items women could answer "yes", "no" or "don't know" (see Table S1 in the Online Supplementary Document). The latter is also considered as an information in the SWPER, but the proportion of women answering "don't know" in these items is too low (generally $<1 \%$ ), causing the multiple imputation not to converge. Thus, we set this information to missing and the imputation process also imputed information (yes/no) for these items. The distribution of the empowerment scores with imputed items was very similar to the distribution of the complete cases (Figure S1 in the Online Supplementary Document). For the MICS surveys, the decision-making items were imputed to allow the calculation of the attitude to violence and social independence domains, but the decision-making domain are only analyzed in the DHS.

\section{Statistical analyses}

We included in the analyses children aged 36-59 months living with the mother at the time of the interview. The ECDI module is only applied for the youngest child in the age range in DHS surveys, so the analyses were also restricted to similar children in MICS to allow comparison. As most of the questions related to women's empowerment available in the surveys were restricted to partnered women, the SWPER global index can only be calculated for this group. Thus, children whose mothers did not have a partner at the time of the survey were not included in the analysis. The proportion of children developmentally on track in each developmental domain using all these restrictions was very similar to the results found considering all children assessed in the surveys (results not shown). Most differences were smaller than 1 percentage point (either positive or negative), with an average of 0.0 percentage points for the literacy-numeracy and social-emotional domains and -0.1 for physical and learning.

We used logistic regression to assess the association between maternal empowerment and child development according to the composite ECDI index as well as each ECDI domain. Crude and adjusted analyses were performed to evaluate whether adjusting for household wealth would affect the results. Preliminary analyses suggested no clear evidence that the sex of the child modified the associations, thus all children were analysed together. Rubin's rules were applied to combine the results of the multiple imputed data sets utilizing the command 'mi estimate' on the statistical software Stata (StataCorp. Stata Statistical Software: release 14. College Station, TX: StataCorp LP; 2015). To get an overall effect and achieve higher statistical power, meta-regressions across countries were performed to assess the pooled odds ratios for the association between empowerment and the child development domains. Meta-regressions combine the results of multiple studies (or, in this case, of multiple countries), weighting each study result by their sample size. Lastly, we performed sensitivity analysis by generating a new social independence measure that excluded the mothers' education and executed the same logistic and meta-regressions to check whether the observed associations would persist. The command 'svy' was used in all the analyses to account for the surveys' sample design. Both DHS and MICS are public sources of information and ethical approval was obtained from the national institutions involved in each survey. 


\section{RESULTS}

Survey data collection ranged from 2010 to 2018, with 18 surveys from West and Central Africa, two from Middle East and North Africa and six from Eastern and Southern Africa (Table 1). In twelve countries (Burundi, Rwanda, Zimbabwe, Benin, Central African Republic, Chad, Cote d'Ivoire, Guinea, Guinea-Bissau, Mali, Senegal and Togo), less than 10\% of the children were on track on literacy-numeracy. Ghana and Tunisia presented the best performance in this domain, with $29.3 \%$ and $39.9 \%$ of the children being on track, respectively. The average proportion across all countries was $15.1 \%$. A vast majority of children were considered on track for the physical and learning developmental domains (92.3\% and 81.3\%, respectively). The physical domain showed the smallest variability across countries, ranging from $83.5 \%$ in Chad to $97.4 \%$ in Ghana. Regarding the social-emotional domain, $67.8 \%$ of the children were on track, on average. Overall, $59.0 \%$ of the children were on track for the composite ECDI (ie, on track in at least three out of the four domains). Chad presented the worst performance, with only $32.1 \%$ of the children on track on the composite ECDI, contrasting with Tunisia where more than $80 \%$ of children were on track (Table 1).

Figure 1, Figure 2, Figure 3, Figure 4 present the crude associations between the mothers' empowerment level as measured by the three domains of the SWPER global (attitude to violence, social independence and decision-making) and each child developmental domain separately. The effect measures can be interpreted as odds ratios for a standard deviation increase in the SWPER global score. The figures also present the overall associations for all the countries, weighted by their sample sizes.

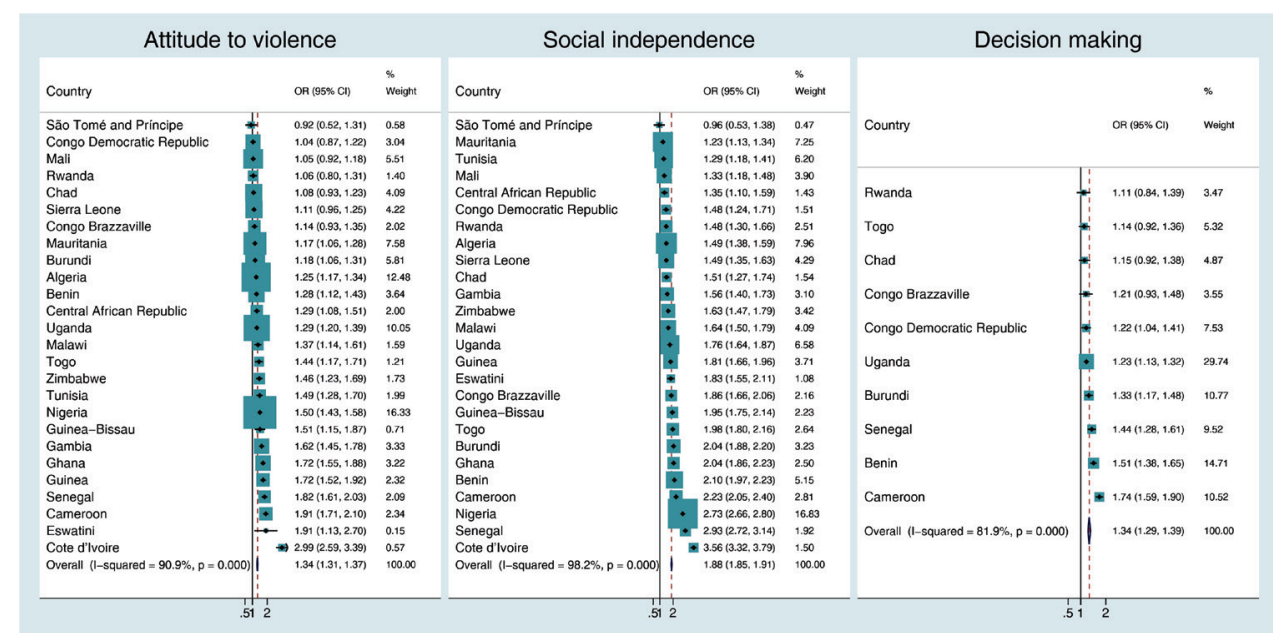

Figure 1. Association between literacy-numeracy development of the child and the mothers' empowerment level for each SWPER global domain. Coefficients are the crude odds ratios (OR) for a standard deviation increase in the SWPER global score.

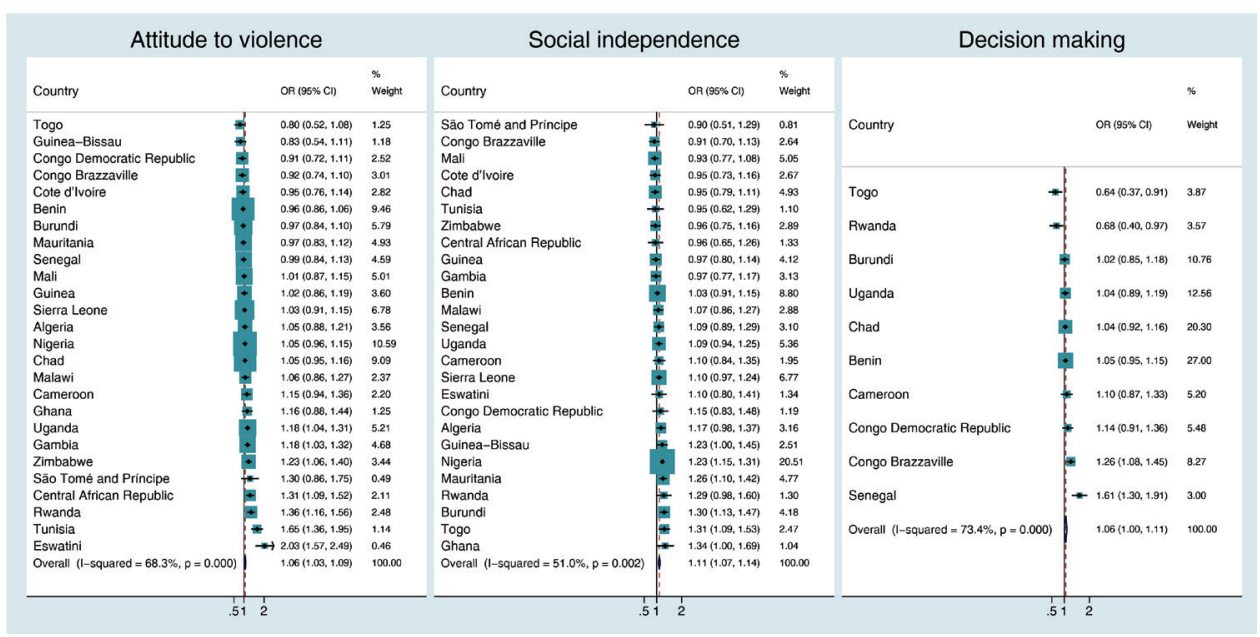

Figure 2. Association between physical development of the child and the mothers' empowerment level for each SWPER global domain. Coefficients are the crude odds ratios (OR) for a standard deviation increase in the SWPER global score. 


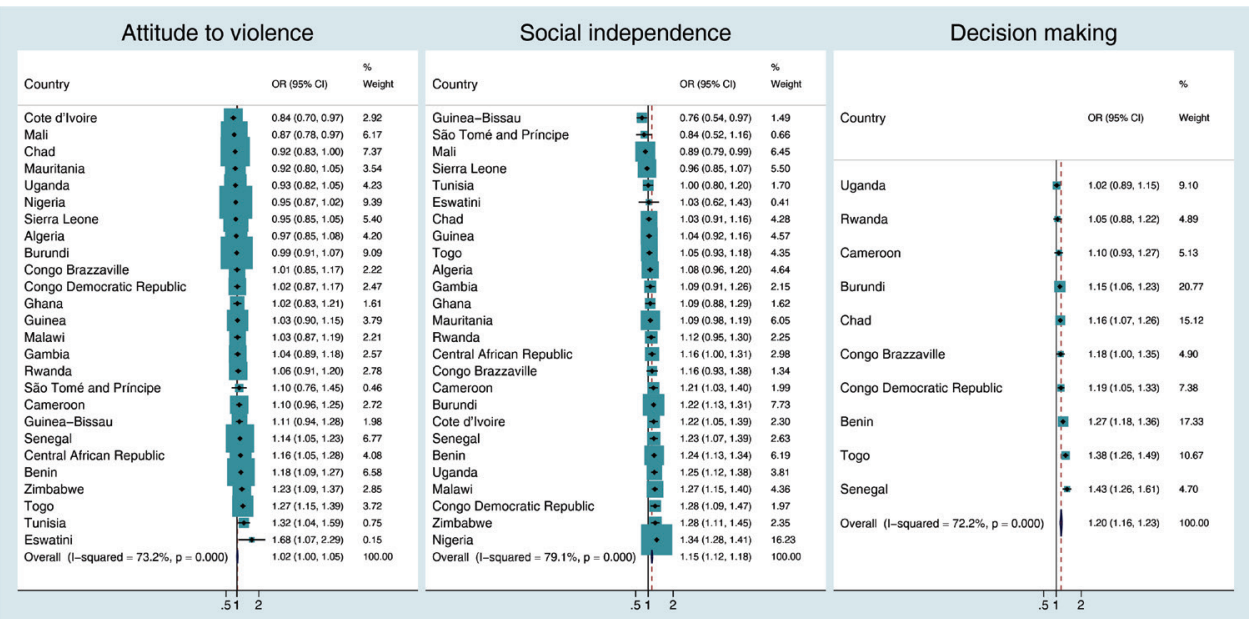

Figure 3. Association between learning development of the child and the mothers' empowerment level for each SWPER global domain. Coefficients are the crude odds ratios (OR) for a standard deviation increase in the SWPER global score.

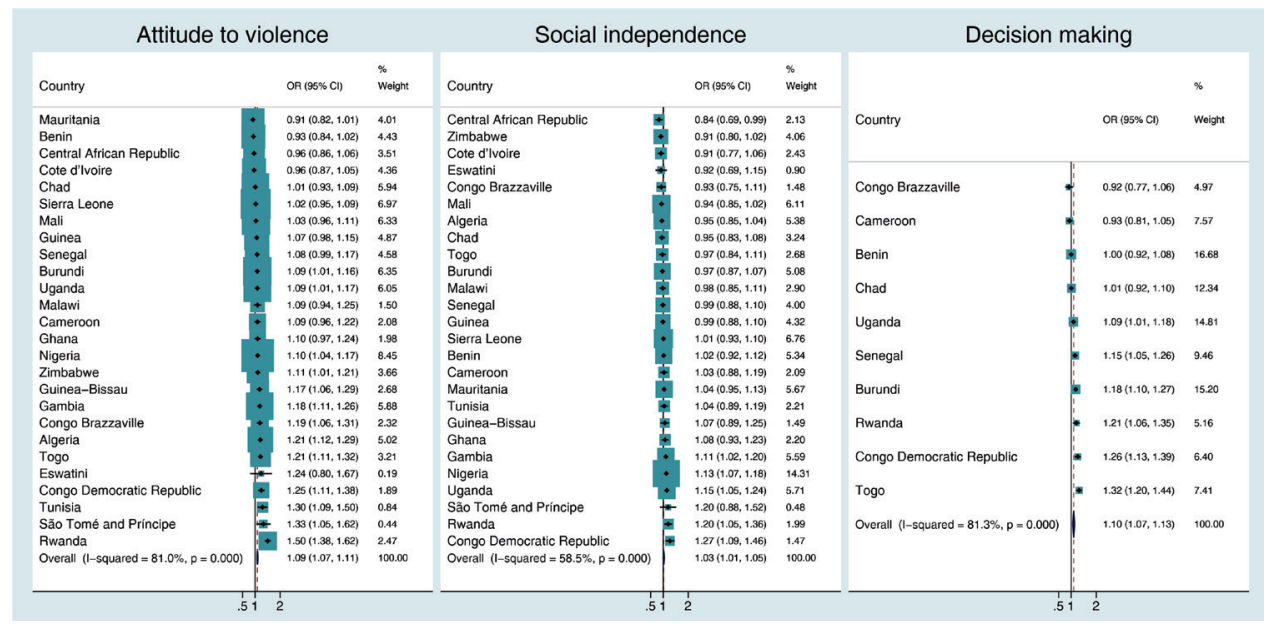

Figure 4. Association between socio-emotional development of the child and the mothers' empowerment level for each SWPER global domain. Coefficients are the crude odds ratios (OR) for a standard deviation increase in the SWPER global score.

There was substantial heterogeneity in the effects of empowerment on child development among countries. For attitude to violence the associations with literacy-numeracy development tended to be positive, but in seven out of 26 countries the confidence intervals included the unity (Figure 1). All countries presented positive associations between mother's social independence and literacy-numeracy scores, except for São Tome and Principe there was no association ( $\mathrm{OR}=0.93 ; 95 \% \mathrm{CI}=0.53-1.38)$. In Cote d'Ivoire one standard deviation in the mother's attitude to violence or social independence increased the odds of the child being on track in literacy-numeracy by 3-fold ( $\mathrm{OR}=2.99 ; 95 \% \mathrm{CI}=2.59-3.39$ for attitude to violence and $\mathrm{OR}=3.56 ; 95 \% \mathrm{CI}=3.32-3.79$ for social independence). Fewer countries had information on the decision-making score, but associations also tended to be positive. Overall, for each standard deviation increase in attitude to violence, social independence and decision-making scores, the pooled odds for the child being on track on literacy-numeracy increased 34\% $(\mathrm{OR}=1.34 ; 95 \% \mathrm{CI}=1.31-1.37$ $\left.\mathrm{I}^{2}=90.9 \%\right), 88 \%\left(\mathrm{OR}=1.88 ; 95 \% \mathrm{CI}=1.85-1.91 ; \mathrm{I}^{2}=98.2 \%\right)$ and $34 \%(\mathrm{OR}=1.34 ; 95 \% \mathrm{CI}=1.29-1.39$; $\left.I^{2}=81.9 \%\right)$, respectively. We performed sensitivity analyses by excluding education from the social independence domain, as it could be driving the positive results. However, the overall association was not strongly affected by this change (pooled $\mathrm{OR}=1.72 ; 95 \% \mathrm{CI}=1.69-1.75$ ).

Generally, the associations between the three empowerment domains and the physical, learning and social-emotional development of the child were small (Figure 2, Figure 3, Figure 4). The pooled odds ratios for physical development were 1.06 (95\% CI=1.03-1.09; $\left.\mathrm{I}^{2}=68.3 \%\right), 1.11$ (95\% CI=1.07-1.14; $\left.\mathrm{I}^{2}=51 \%\right)$ and $1.06\left(95 \% \mathrm{CI}=1.00-1.11 ; \mathrm{I}^{2}=73.4 \%\right)$, respectively, for attitude to violence, social independence and decision-making domains. 
We repeated the analyses after adjusting for household wealth. These results can be found in Figures S2S5 in the Online Supplementary Document. Generally, the associations between empowerment and the literacy-numeracy scores were markedly attenuated, but the patterns remain similar to the crude analyses. After such adjustment, each additional standard deviation in attitude to violence, social independence and decision-making increased the pooled odds of being on track in literacy-numeracy by $11 \%(\mathrm{OR}=1.11$; $95 \% \mathrm{CI}=1.08-1.14), 34 \%(\mathrm{OR}=1.34 ; 95 \% \mathrm{CI}=1.31-1.37)$ and $18 \%(\mathrm{OR}=1.18 ; 95 \% \mathrm{CI}=1.13-1.23)$, respectively. In the other domains, with a few exceptions, the overall associations were very small or null after adjustment by wealth. The combined associations of attitude to violence and social independence on the physical development of the child after adjustment were reduced to 3\% (OR $=1.03 ; 95 \%$ $\mathrm{CI}=1.00-1.06)$ and $5 \%(\mathrm{OR}=1.05 ; 95 \% \mathrm{CI}=1.01-1.08)$, respectively. A similar situation happened for the associations of attitude to violence and decision making on the social-emotional development of the child where the pooled odds were reduced to $8 \%(\mathrm{OR}=1.08 ; 95 \% \mathrm{CI}=1.06-1.10)$ and $9 \%(\mathrm{OR}=1.09$; $95 \% \mathrm{CI}=1.06-1.12)$, respectively. For the learning development, social independence and decision-making domains, the odds of the child being on track increased by $4 \%(\mathrm{OR}=1.04 ; 95 \% \mathrm{CI} 1.01-1.07)$ and $16 \%(\mathrm{OR}=1.16 ; 95 \% \mathrm{CI}=1.12-1.20)$ for each standard deviation increase in the mothers' empowerment scores after adjustment.

We also analyzed associations with the composite ECDI score (Figure S6 in the Online Supplementary Document). Overall, the unadjusted pooled odds for the attitude to violence, social independence and decision-making domains were, respectively, of $11 \%(\mathrm{OR}=1.11$; 95\% CI $=1.09-1.13), 21 \%(\mathrm{OR}=1.21$; 95\% CI $=1.19-1.23)$ and $19 \%(O R=1.19 ; 95 \% C I=1.16-1.22)$ on the ECDI. With a few exceptions Chad, Mali, Cote d'Tvoire, Mauritania and Sierra Leone in attitude to violence and Mali and Sao Tome and Principe in social independence - all countries presented positive associations. After adjustment for wealth, the overall odds were reduced to $5 \%\left(\mathrm{OR}=1.05 ; 95 \% \mathrm{CI}=1.03-1.07 ; \mathrm{I}^{2}=77.4 \%\right), 8 \%(\mathrm{OR}=1.08$; $\left.95 \% \mathrm{CI}=1.06-1.11 ; \mathrm{I}^{2}=64 \%\right)$ and $15 \%\left(\mathrm{OR}=1.15 ; 95 \% \mathrm{CI}=1.11-1.18 ; \mathrm{I}^{2}=61.9 \%\right)$ for the attitude to violence, social independence and decision-making domains, respectively (Figure S7 in the Online Supplementary Document).

\section{DISCUSSION}

To our knowledge, no study to date has examined the associations between women's empowerment and ECD in LMICs. On average, $15.1 \%, 92.3 \%, 81.3 \%$ and $67.8 \%$ of the children were on track for literacy-numeracy, physical, learning and socioemotional developmental domains, respectively. Despite substantial heterogeneity between countries in the association of mother's empowerment with ECD, we showed that generally higher maternal empowerment levels - particularly for the social independence domain - were strongly associated with the acquisition of literacy-numeracy skills in several African countries. In contrast, the mothers' empowerment level presented weak or null associations with the three other developmental domains.

In the African context, where many countries are still struggling to have reliable data on child health, obtaining valid and representative data on child development remains a major challenge [2,7]. The ECDI was developed by UNICEF in order to fill this gap, yet this indicator is not free of limitations. Almost all children were on track in the physical and learning domains, which suggests the presence of a ceiling effect for these measures. Generally, the items comprised in both domains are easily achieved, so that almost all children are considered as being on track. The weak associations between empowerment (as it would be expected with any other predictor) and these two domains may be due to the tests' inability to detect children who present less marked degrees of impairment. For example, in the physical domain, the pincer grasp item represents a skill normally developed before one year of age, so it would only capture severe developmental setbacks in children aged 36-59 months [21] . The same authors argue that being too sick to play - also in the physical domain - would represent the children's health status rather than their early developmental skills.

We found that each additional standard deviation in the social independence empowerment level of the mother was associated with an almost doubling in the child's odds of being on track on literacy-numeracy. This empowerment domain is comprised by items related to the woman's education, ages at first birth and at first cohabitation, and the differences in age and education between the woman and her partner. There is a large body of literature reporting on the effect of parental education on the development of the child $[6,24,25]$. However, our sensitivity analyses showed that this association was not solely driven by education, suggesting that it represents a possible effect of the social independence as a whole. 
In spite of the limitations of the ECDI, the availability of a cross-culturally validated standard measure is an extremely valuable advance in the field. In many LMICs, this is the only child development measure available. The ECDI opens innumerable new research opportunities and has potential to make governments and policy makers accountable regarding the countries' advances. However, the ceiling effects may indicate that the ECDI will require adjustments to allow the monitoring of the progress towards the 2030 SDGs.

Our study has limitations that should be considered while interpreting the findings. Female-headed households are generally more likely to face poverty and possibly poor health outcomes than those where the child's father is also present [26], yet as it currently stands, the women's empowerment measure can only be calculated for women who were in a union; in the surveys included in the analyses, the median proportion of female-headed households was $25.2 \%$ (range from $8.1 \%$ to $45.6 \%$ ). Additionally, children who do not live with their mothers were not included in our analyses. Therefore, we cannot extrapolate the results to all children aged 36-59 months in the countries analyzed, but the ones included in our study are certainly the large majority. Also, the heterogeneity of the effects between countries was quite high, so the pooled effect estimated in the metanalyses should be interpreted with caution. Further studies are necessary to identify the possible reasons for the high heterogeneity.

Women's empowerment is strongly associated with family socioeconomic characteristics $[23,27]$. This association is complex, because poverty may contribute to reduce empowerment, but on the other hand empowered women are more likely to work outside the home and contribute to household income [28]. ECD is also closely associated with family wealth [29]. By adjusting the analyses for household wealth, we aimed to evaluate whether the association between empowerment and child development persisted. After adjustment, the association was substantially attenuated - for example, the odds for literacy-numeracy according to social independence fell from 1.90 to 1.35. Other odds ratios also showed less marked attenuation, but the associations remained positive (results presented in Appendix S1 of the Online Supplementary Document). One should, however, be careful while interpreting these associations, given that the relationship between wealth and women's empowerment is complex and possibly bidirectional. By adjusting the association by wealth, we attempt to account for it as a confounder. But it is also possible that wealth is part of the pathway linking empowerment to child development.

Empowering women is a goal in itself, but it also has a great potential to improve health and economic outcomes both at household and community level. We showed that maternal empowerment is associated with better ECD in the literacy-numeracy domain. Thus, programs and interventions aimed at improving the future human capital of today's children may also consider addressing the empowerment of women and the reduction of gender inequalities.

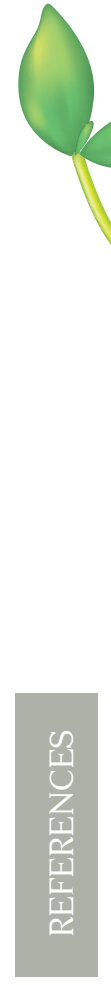

Funding: The study was funded by the Bill \& Melinda Gates Foundation [Grant Number: OPP1199234], Wellcome [Grant Number: 101815/Z/13/Z] and Associação Brasileira de Saúde Coletiva (ABRASCO). The funders of the study had no role in the data analysis, data interpretation, or writing of the paper. The corresponding author had full access to all the data and had final responsibility for the decision to submit it for publication.

Authors contributions: FE conceptualized and designed the study, carried out the analysis and drafted the initial manuscript. Prof Lynch, Mittinty, Raj and Victora reviewed and revised the final manuscript. Coll contributed to the writing of the manuscript, reviewed and revised the final manuscript. Prof Barros conceptualized the study, advised on the analysis, reviewed and revised the final manuscript.All authors approved the final manuscript as submitted and agree to be accountable for all aspects of the work.

Competing interests: The authors completed the ICMJE Unified Competing Interest form (available upon request from the corresponding author), and declare no conflicts of interest.

Additional material

Online Supplementary Document

1 Grantham-McGregor S, Cheung YB, Cueto S, Glewwe P, Richter L, Strupp B, et al. Developmental potential in the first 5 years for children in developing countries. Lancet. 2007;369:60-70. Medline:17208643 doi:10.1016/S0140-6736(07)60032-4

2 Richter LM, Daelmans B, Lombardi J, Heymann J, Boo F, Behrman J, et al. Investing in the foundation of sustainable development: pathways to scale up for early childhood development. Lancet. 2017;389:103-18. Medline:27717610 doi:10.1016/S0140-6736(16)31698-1

3 Chan M, Lake A, Hansen K. The early years: silent emergency or unique opportunity? Lancet. 2017;389:11-3. Medline:27717612 doi:10.1016/S0140-6736(16)31701-9 
4 Cappa C, Section A. The formative years: UNICEF' s work on measuring early childhood development. New York: Division of Data, Analytics, Planning and Monitoring (DAPM), UNICEF; 2019.

5 Walker SP, Wachs TD, Grantham-mcgregor S, Black MM, Nelson CA, Huffman SL, et al. Inequality in early childhood: risk and protective factors for early child development. Lancet. 2011;378:1325-38. Medline:21944375 doi:10.1016/ S0140-6736(11)60555-2

6 Black MM, Walker SP, Fernald LCH, Andersen CT, DiGirolamo AM, Lu C, et al. Early childhood development coming of age: science through the life course. Lancet. 2017;389:77-90. Medline:27717614 doi:10.1016/S0140-6736(16)31389-7

7 Daelmans B, Darmstadt GL, Lombardi J, Black MM, Britto PR, Lye S, et al. Early childhood development: the foundation of sustainable development. Lancet. 2017;389:9-11. Medline:27717607 doi:10.1016/S0140-6736(16)31659-2

8 Gashaw BT, Magnus JH, Schei B. Intimate partner violence and late entry into antenatal care in Ethiopia. Women Birth. 2019;32:e530-7. Medline:30595351 doi:10.1016/j.wombi.2018.12.008

9 Greene CA, Chan G, McCarthy KJ, Wackschlag LS, Briggs-Gowan MJ. Psychological and physical intimate partner violence and young children's mental health: The role of maternal posttraumatic stress symptoms and parenting behaviors. Child Abuse Negl. 2018;77:168-79. Medline:29358121 doi:10.1016/j.chiabu.2018.01.012

10 World Economic Forum. The Global Gender Gap Report 2016 Insight Report. 2016.

11 Ewerling F, Raj A, Victora CG, Hellwig F, Coll CVN, Barros AJD. SWPER Global: A survey-based women's empowerment index expanded from Africa to all low- and middle-income countries. Available: https://www.medrxiv.org/content/10.1 101/2020.07.31.20166223v1. Accessed: 20 October 2020.

12 Horton R. Offline: Gender equality—the neglected SDG for health. Lancet. 2015;386:1928. doi:10.1016/S01406736(15)00945-9

13 Ahmed S, Creanga AA, Gillespie DG, Tsui AO. Economic status, education and empowerment: Implications for maternal health service utilization in developing countries. PLoS One. 2010;5:e11190. Medline:20585646 doi:10.1371/ journal.pone.0011190

14 Tadesse M, Teklie H, Yazew G, Gebreselassie T. Women's Empowerment as a Determinant of Contraceptive use in Ethiopia Further Analysis of the 2011 Ethiopia Demographic and Health Survey. DHS Furth Anal Reports. $2013 ; 82$.

15 Msuya SE, Adinan J, Mosha N. Intimate partner violence and empowerment among women in Tanzania: Prevalence and effects on utilization of reproductive and maternal health services. DHS Work Pap No 106.2014.

16 Prata N, Fraser A, Huchko MJ, Withers M, Lewis S, Ciaraldi EJ, et al. Women's empowerment and family planning: A review of the literature. J Biosoc Sci. 2017;49:713-43. Medline:28069078 doi:10.1017/S0021932016000663

17 Nasrullah M, Zakar R, Kramer A. Effect of child marriage on use of maternal health care services in Pakistan. Obstet Gynecol. 2013;122:517-24. Medline:23921855 doi:10.1097/AOG.0b013e31829b5294

18 Upadhyay UD, Gipson JD, Withers M, Lewis S, Ciaraldi EJ, Fraser A, et al. Women's empowerment and fertility: A review of the literature. Soc Sci Med. 2014;115:111-20. Medline:24955875 doi:10.1016/j.socscimed.2014.06.014

$19 \mathrm{Na}$ M, Jennings L, Talegawkar SA, Ahmed S. Association between women's empowerment and infant and child feeding practices in sub-Saharan Africa: An analysis of Demographic and Health Surveys. Public Health Nutr. 2015;18:3155-65. Medline:26347195 doi:10.1017/S1368980015002621

20 World Economic Forum. The Global Gender Gap Report. Geneva: 2017.

21 McCoy DC, Peet ED, Ezzati M, Danaei G, Black MM, Sudfeld C, et al. Early Childhood Developmental Status in Lowand Middle-Income Countries: National, Regional, and Global Prevalence Estimates Using Predictive Modeling. PLoS Med. 2016;13:e1002034. Medline:27270467 doi:10.1371/journal.pmed.1002034

22 Ewerling F, Raj A, Victora CG, Hellwig F, Coll CVN, Barros AJD. A Survey-Based Women's Empowerment Index for Low-and Middle-Income Countries: The SWPER Goes Global. Available: https://ssrn.com/abstract=3466986. Accessed: 9 October 2019.

23 Ewerling F, Lynch JW, Victora CG, van Eerdewijk A, Tyszler M, Barros AJD. The SWPER index for women's empowerment in Africa: Development and validation of an index based on survey data. Lancet Glob Health. 2017;5:e916-23. Medline:28755895 doi:10.1016/S2214-109X(17)30292-9

24 Walker SP, Wachs TD, Gardner JM, Lozoff B, Wasserman GA, Pollitt E, et al. Child development: risk factors for adverse outcomes in developing countries. Lancet. 2007;369:145-57. Medline:17223478 doi:10.1016/S0140-6736(07)60076-2

25 Richter LM, Daelmans B, Lombardi J, Heymann J, Boo FL, Behrman JR, et al. Investing in the foundation of sustainable development: pathways to scale up for early childhood development. Lancet. 2017;389:103-18. Medline:27717610 doi:10.1016/S0140-6736(16)31698-1

26 Clark S, Hamplová D. Single motherhood and child mortality in sub-Saharan Africa: A life course perspective. Demography. 2013;50:1521-49. Medline:23839100 doi:10.1007/s13524-013-0220-6

27 Bushra A, Wajiha N. Assessing the Socio-economic Determinants of Women Empowerment in Pakistan. Procedia Soc Behav Sci. 2015;177:3-8. doi:10.1016/j.sbspro.2015.02.321

28 Lailulo YA, Susuman AS, Blignaut R. Correlates of gender characteristics, health and empowerment of women in Ethiopia. BMC Womens Health. 2015;15:116. Medline:26643729 doi:10.1186/s12905-015-0273-3

29 Shanks TRW. The Impacts of Household Wealth on Child Development. J Poverty. 2007;11:93-116. doi:10.1300/ J134v11n02_05 